\title{
Cotidiano
}

\section{A REPRESENTAÇÃO DO LIXO PARA O INFANTE CATADOR}

Gislaine Farias de Oliveira(1)

Hidemburgo Gonçalves Rocha(2)

Nas ciências sociais, o estudo das representações sociais remonta ao século passado. Vários autores procuram discutir ainda hoje, a importância das representações dentro de uma coletividade e como elas influem das decisões que os seres humanos tomam individualmente. Deve-se observar que as representações individuais não podem ser ampliadas para a coletividade, mas o contrário sim (REIGOTA, 2001). Portanto, o que vem a ser Ciências sociais? Representação social? Decisões? Coletividade? Qual a importância da representação social na tomada de decisão sobre o ambiente em que se vive? E finalmente o que representa o lixo para a criança que sobrevive da catação?

As Ciências Sociais, refere-se ao estudo da sociedade e o comportamento do indivíduo em seu meio social, dessa forma a Representação Social (ou modo de pensar), aparece como sendo o senso comum que se tem sobre um determinado tema, onde se incluem também os preconceitos, e características específicas das atividades cotidianas (sociais e profissionais) das pessoas (REIGOTA, 2001). A coletividade que é a sociedade em si, está inserida nesse contexto. O indivíduo como um todo, contemporaneamente, desenvolve seu próprio modo de pensar a respeito das coisas que o rodeiam, incluindo o meio em que vive, seu senso de observação permite decidir, quando consciente, a maneira correta de como agir para melhorar suas condições de vida e o meio em que vive. A representação do lixo para o infante catador, necessita de uma análise mais profunda. A criança não fundamenta a respeito desse assunto, por não pensar no lixo como forma indispensável à sua sobrevivência, levando em consideração em que condições exercem essa atividade.

Nessas circunstâncias nos perguntamos: Como o infante catador e sua família enfrentam a problemática sóciocultural, econômica ou ambiental? 


\section{O Desemprego no Brasil}

O desemprego tornou-se uma epidemia nos países pobres, e agravou-se com a globalização econômica, o trabalho com materiais recicláveis aparece como uma oportunidade de trabalho, ainda que informal. O Brasil tem a quinta maior população do mundo e o segundo maior contingente de desempregados em números absolutos (IBGE, 2000). A evolução do número de desempregados reforça a crise no mercado de trabalho no país. Em cada cinco trabalhadores, um não consegue um lugar no mercado de trabalho, levando em média dois anos para conseguir um novo emprego. Infelizmente, o Brasil só perde para a Índia em números de desempregados. Como alternativa de fugir do desemprego e resgatar a cidadania, essas pessoas que já somam mais de 100 mil, incluindo crianças e adolescentes, trabalham na catação, tendo-se, em alguns lugares, três gerações de uma mesma família vivendo no e do lixo. A situação destas pessoas é extremamente cruel: expostas a doenças através de vetores (moscas, ratos, baratas), mutilações e risco de vida. Elas estão privadas de educação, lazer, moradia, saúde, afeto, e convivem com marginalidade, prostituição, uso indevido de drogas, sem qualquer perspectiva de um futuro digno.

\section{Lixo Uma Antiga Forma de Sobrevivência}

Há mais de 50 (cinqüenta) anos, a figura do catador surgiu compondo o cenário das cidades brasileiras. Muitos eram pedreiros, marceneiros ou tinham outra profissão, tornaramse catadores após perder o emprego. O desemprego, inegavelmente crescente nas grandes cidades leva cada vez mais brasileiros buscarem outra alternativa de sobrevivência. Criativos esses desempregados encontram no lixo um meio para garantir o sustento familiar. Essa população que migra de diversas localidades, instalam-se na periferia das cidades buscado aproximação com áreas de predominância da classe média alta, onde o lixo é mais rico e em maior quantidade. Contudo, os valores por quilo dos materiais recolhidos são insignificantes, necessitando uma grande quantidade de cada material para garantir alguns trocados no dia. Dessa forma os pais percorrem as ruas ou lixões levando consigo seus filhos menores e inevitavelmente a catação torna-se uma atividade hereditária, que passa de pai para filho. Em todo o Brasil, muitos são os catadores, agora já adultos, que foram criados pelos pais com o dinheiro da catação. Vale a pena ressaltar que não há registro de nenhuma outra atividade que, simultaneamente produza bens e colabore com serviços para a sociedade. 
Entende-se por infante catador a criança que contribui com a natureza, e com o complemento da renda familiar catando do lixo materiais que podem ser reciclando. Essas crianças, marginalizadas, inconscientemente protegem a natureza sem o devido conhecimento sobre a importância do que fazem. Perdem sua infância, nas ruas ou em aterros sanitários, retirando do lixo produtos que podem ser vendidos para indústrias de transformação e novamente transformados em outros produtos. Muitas abandonam a escola. São crianças que em vez de estudar, perdem oportunidades de vida, percorrendo ruas ou permanecendo com seus pais nos lixões para contribuir com a renda familiar. Contudo, a criança quer brincar. Precisa brincar, jogar, fantasiar mundos e construir as trilhas do conhecimento sobre a realidade. Criança sonha ser acalentada e protegida. Espera que alguém, a defenda, a ajude a enfrentar as dificuldades que a vida lhes apresenta. É triste ver crianças perderem a infância trocando o sonho por trabalho.

A realidade vivida do trabalho infanto-juvenil proveniente da catação nas ruas e nos lixões, apresenta-se duplamente indigno, esse tipo de atividade rouba-lhes o precioso tempo de construção de um projeto futuro, rouba-lhes também, o direito a educação, ao lazer, a moradia, impondo uma realidade ausente de perspectivas de vida, o que contraria todos os princípios e compromissos do Estado e da sociedade, de proteção à infância e a adolescência brasileira, comprometendo o nosso futuro como nação.

\section{O que é Lixo?}

A Organização Pan Americana de Saúde adota a definição de lixo como sendo todo o resíduo sólido putrecível e não putrecível (exceto excreção humana). O lixo inclui desperdícios, dejetos, cinzas, produto de varrição de ruas, animais mortos, automóveis abandonados e restos sólidos procedentes de mercados e indústrias.(SILVA, 1999). O lixo é um interminável ciclo de morte, decomposição, nova vida e crescimento. Logo, o que é lixo para algumas espécies, é riqueza para outras. (JAMES, 2002).

Até recentemente, a humanidade não havia percebido que o volumoso lixo produzido, é um grave problema sócioambiental. Sem as mínimas condições de permanecer em nossas residências ou jogados de qualquer forma nas vias públicas. Por isso são destinados a um determinado local, escolhido pelas prefeituras. Esse espaço geográfico denominado de aterros sanitários ou simplesmente lixões, recebem os resíduos sólidos que diariamente nós descartamos na urbe, é nesse espaço onde aglomeram-se indivíduos e seus familiares em busca de sobrevivência. (SCARLATO, 2002). 
A catação nos lixões, assim como a catação na rua, não é apenas um sintoma da crise econômica pela qual o Brasil tem passado, tornou-se uma opção de vida para milhares de brasileiros. A maioria desconhece outra forma de viver, por terem sido criados nesses locais e tendo como residência os barracos ali instalados.

Para a sociedade, o procedimento de desfazer-se do seu lixo não passa de uma ação rotineira e sem a menor importância. Um problema que aparentemente de fácil solução para as prefeituras. Contudo, a simples ação do indivíduo descartar seus resíduos sólidos, é apontada como grave problema social e ambiental nos mais diversos centros urbanos não só do Brasil, mas do Mundo. Principalmente naqueles em que sua capacidade de produção é acentuada, em decorrência do desenvolvimento industrial, do crescimento populacional e do consumismo.

O quantitativo de lixo produzido por uma urbe encontra-se estritamente relacionado com o desenvolvimento industrial, Esse tipo de lixo apresenta outra categoria de detritos urbanos resultante da operação das fábricas. Sua constituição depende do ramo de atividade da industria, que pode produzir filmes para fotografia, sabão em pó, eletrodoméstico e peças para aviões.

Essa enorme montanha de lixo, composta principalmente de resíduos orgânicos, misturados com embalagens, vasilhames, jornais, louças e objetos quebrados, provêm da nossa própria casa. Denominado de lixo doméstico ou domiciliar resulta das nossas atividades cotidianas de: limpar a casa cozinhar, ir ao banheiro, estudar. No Brasil, segundo estimativas, cada pessoa produz em média cerca de $500 \mathrm{~g}$ de resíduos por dia, sendo metade desse peso correspondente a sobras de alimento. (RODRIGUES, 2001)

Como a destinação final de todo o lixo recolhido nas cidades é o aterro sanitário, a diversificação de materiais encontrados nesses locais, são incontáveis, inclui inclusive embalagens contendo substância tóxicas descartadas nas mesmas condições de um lixo qualquer. O lixo tóxico dobra a preocupação da administração municipal, a população não possui informações suficientes sobre o lixo tóxico que a cidade produz, para onde é levado, como é armazenado e quem o transporta. Por não possuírem conhecimento sobre esse tipo de lixo os indivíduos ficam mais expostos à contaminação. Nesse ambiente infecto e tão insalubre encontramos crianças brincando com naturalidade. (SILVA, 1999).

O lixo brasileiro é considerado um dos mais ricos do mundo e sua reciclagem é fortemente sustentada pela catação informal, os chamados garimpeiros do lixo, que executam essa atividade sem nenhuma orientação. A sociedade como um todo desconhece questões relativas a saneamento ambiental, em especial qual o objetivo das prefeituras municipais em 
sistematizar à coleta e destinação adequada dos resíduos ou como identificar os materiais de difícil degradação.

\section{Aterro Sanitário}

Os aterros sanitários hoje, constituem uma grande preocupação se levarmos em conta, que o lixo é um problema também para o meio ambiente quando o seu volume cresce indiscriminadamente, provocando poluição do ar, da água, do solo, e pouco se tem feito para contornar esse aspecto. Esse mesmo lixo torna-se um problema econômico por caracterizar-se destruidor e desperdiçador de riquezas naturais, além de consumir recursos financeiros na operacionalização do processo de remoção das ruas e destiná-lo aos lixões. (SCARLATO, 2002).

O descarte aleatório dos resíduos em nascentes, córregos, canais, margens de rios e estradas, além de provocar problemas ambientais graves e poluir as águas, que muitas vezes são captadas para consumo, atrai um exército de desempregados e famintos, que sobrevivem à custa da cata de resíduos para a sua alimentação e para comercialização.

A administração do lixo já é hoje uma das grandes preocupações na organização urbana. Qualquer cidade, por menor que seja, concentra uma quantidade considerável de entulho, o que ocasiona problemas à administração municipal. Leva-se em conta que amontoados de lixo deixados nas calçadas, terrenos baldios ou mesmo jogados nas vias públicas, rapidamente transforma-se em ninho de ratos, baratas, escorpiões, etc.(RODRIGUES, 2001). Podemos citar ainda, o lixo recolhido pelo serviço de conservação urbana, como: poda de árvores, varrição de ruas e praças, corte do mato, limpeza de bueiros e canais, retirada de animais mortos das vias públicas e entulhos deixados nas construções.

\section{Um problema de ordem social}

É visto como problema social, pelos aspectos epidemiológicos causando inúmeras doenças, as quais são manifestados por agentes patogênicos, todos procriados em função da convivência diária com o lixo. Outro aspecto também social refere-se ao quadro desumano observado nas ruas e nos lixões, a catação é uma atividade que envolve a família inteira, esta, por ser extremamente carente, necessita da colaboração de todos os membros, o que inclui os filhos que em idade muito tenra, se sacrificam retirando migalhas que podem ser 
recolhidas com antecedência através da coleta seletiva. Por último o aspecto cultural, que é retratado em palestras por especialistas e políticos como sendo um problema educacional, onde inúmeros discursos são proferidos que resultam em mudanças socialmente insignificantes. A atividade desses trabalhadores apresenta uma solução possível para os principais problemas das cidades que são a pobreza, a falta de oportunidades de emprego e renda. (SILVA, 1999)

Educação ambiental, não é somente a aquisição de conhecimento, mas também a mudança de comportamento, a determinação para a ação e a busca de soluções para os problemas. Em geral promovida na escola, a qual o infante catador não tem acesso. A educação ambiental está ligada diretamente às regras de cidadania.(VITORINO, 2000)

Sabemos que estudos sobre crianças que catam (recicladoras) ainda são precários. Para o Infante Catador o lixo tem representado: alimento, trabalho e moradia. A catação é uma forma (ainda que muito pequena) de resgatar a cidadania. Mas, certas evidências, como algumas denúncias veiculadas na mídia, pelas ONG's e pelos movimentos que trabalham com crianças, permitem-nos formular algumas hipóteses com relação à erradicação do trabalho infanto-juvenil.

O desafio do poder público, das instituições religiosas e ONG's, que desenvolvem trabalhos com crianças recicladoras, é de orientar o encaminhamento dessas crianças e jovens para as escolas. Solicitando que as mesmas priorizem vagas para as crianças e adolescentes que vivem da catação do lixo.

Além disso, um dos desafios tem sido enfrentar os preconceitos por parte dos professores, servidores, diretores e alunos em relação às crianças que vivem em locais como os lixões, e ajudá-las em sua adaptação e integração ao universo escolar. A partir de um diagnóstico epidemiológico dessas crianças, é possível detectar os maiores problemas que afetam, principalmente as que sofrem com doenças de pele, respiratórias e desnutrição, tendo como objetivo implementar as intervenções necessárias. Já os adolescentes necessitam de orientação nas questões relativas doenças sexualmente transmissíveis, AIDS e drogas.

\section{Referências}

FERrEIRA, Aurélio Buarque de Holanda. Pequeno Dicionário da Língua Portuguesa. Rio de Janeiro- RJ, Ed. Civilização Brasileira Ltda, 1974. 
JAMES, BÁRBARA. Lixo e Reciclagem: coleção preserve o mundo. - São Paulo, SP: Scipione, 1997.

REIGOTA, Marcos. Meio Ambiente e Representação Social. - São Paulo, SP : Cortez, 2001.

REIGOTA, Marcos.Verde Cotidiano: o meio ambiente em discussão. - São Paulo, SP : Cortez, 2001.

RODRIGUES, LUIZ FRANCISCO. Lixo: de onde vem? para onde vai?. - São Paulo, SP: Moderna, 1997.

SCARLATO, FRANCISCO CAPUANO. Do Nicho ao Lixo: ambiente, sociedade e educação. - São Paulo, SP: Ed. Saraiva, 1992.

VESENTINI, J. WILLIAM. Sociedade e Espaço, São Paulo, SP : Ática, 1992.

VICTORINO, CÉLIA JUREMA AITO. Canibais da Natureza, educação ambiental, limites e qualidades de vida. Petrópolis, RJ : Vozes, 2000.

Sobre os autores:

(1) Gislaine Farias de Oliveira é especialista em Geografia com ênfase nas questões ambientais pela Fundação de Ensino Superior de Olinda - PE. E-mail: gislainefarias44@ @otmail.com .

(2) Hidemburgo Gonçalves Rocha é Mestre em Bioquímica e Professor Adjunto da Universidade Regional do Cariri e da Universidade Federal do Ceará, atuando na Faculdade de Medicina do Cariri. E_mail: hidemburgo.rocha@bol.com.br. 